\title{
Observations of the High-Latitude Ionosphere With the Poker Flat MST Radar: Analyses Using Simultaneous Chatanika Radar Measurements
}

\author{
J. G. LuHManN AND R. M. Johnson
}

Institute of Geophysics and Planetary Physics, University of California, Los Angeles

M. J. BARON ${ }^{1}$

Radio Physics Laboratory, SRI International

\author{
B. B. Balsley AND A. C. RidDle
}

Aeronomy Laboratory, NOAA Environmental Research Laboratories

The NOAA MST (mesosphere-stratosphere-troposphere) VHF radar at Poker Flat, Alaska, provides nearly continuous high time resolution measurements of the velocity of 3-m scale plasma density irregularities at altitudes $\sim 85 \mathrm{~km}$ during the summer and less continuous but lower $(\sim 65 \mathrm{~km})$ altitude observations during the winter. However, incomplete knowledge of the origin and behavior of the VHF scatterers limits the applications of these data. Observations from the nearby Chatanika incoherent scatter radar are used to investigate the effects of electron precipitation and magnetospheric convection electric fields on the VHF observations. It is shown that the backscattered VHF signal is usually enhanced when auroral particles increase the $D$ region ionization. The magnetospheric convection electric fields do not generally affect the interpretation of the measured velocities of the $3-\mathrm{m}$ plasma irregularities as mesospheric winds. Combined neutral wind measurements from the two radars show some evidence for a continuous tide from the mesosphere through the thermosphere.

\section{INTRODUCTION}

The NOAA MST radar at Poker Flat, Alaska [Balsley et al., 1980], has the distinction that it is currently the only radar of its type located in the auroral zone. Like similar VHF radars at low and mid-latitude sites [cf. Röttger, 1980], the Poker Flat radar detects echoes from 3-m scale plasma density irregularities in the $D$ region and lower $E$ region of the ionosphere as well as from meteor trails [cf. Avery et al., 1983].

The reason for the existence of 3-m irregularities at altitudes of $\sim 55 \mathrm{~km}$ to $\sim 95 \mathrm{~km}$ is not fully understood. Although Gage and Balsley [1980], among others, have suggested that turbulence-generated irregularities in the neutral atmosphere will produce comparable scale structure in the ionosphere where a sufficient electron density gradient is present, neutral turbulence with this scale size should be strongly damped by viscosity at the mesospheric altitudes where the VHF echoes originate [Reid et al,, 1981]. Moreover, the characteristics of the scattering volumes, including their morphology and temporal variability, differ at the various MST sites [cf. Röttger, 1980; Ecklund and Balsley, 1981]. Since the nature of the VHF mesospheric echoes is uncertain, the interpretation of the (irregularity) velocities obtained from the Doppler shift of the frequency of MST radar echoes is questionable. In particular, the observed velocities have been considered as a direct measurement of the neutral wind, but Reid [1983] finds that electric fields of magnitudes that are typical in the auroral zone can have a significant effect on the motion of plasma at altitudes down to $85 \mathrm{~km}$.

\footnotetext{
'Now at EISCAT Scientific Association.
}

Copyright 1983 by the American Geophysical Union.

Paper number $3 \mathrm{~A} 1400$.

0148-0227/83/003A-1400\$05.00

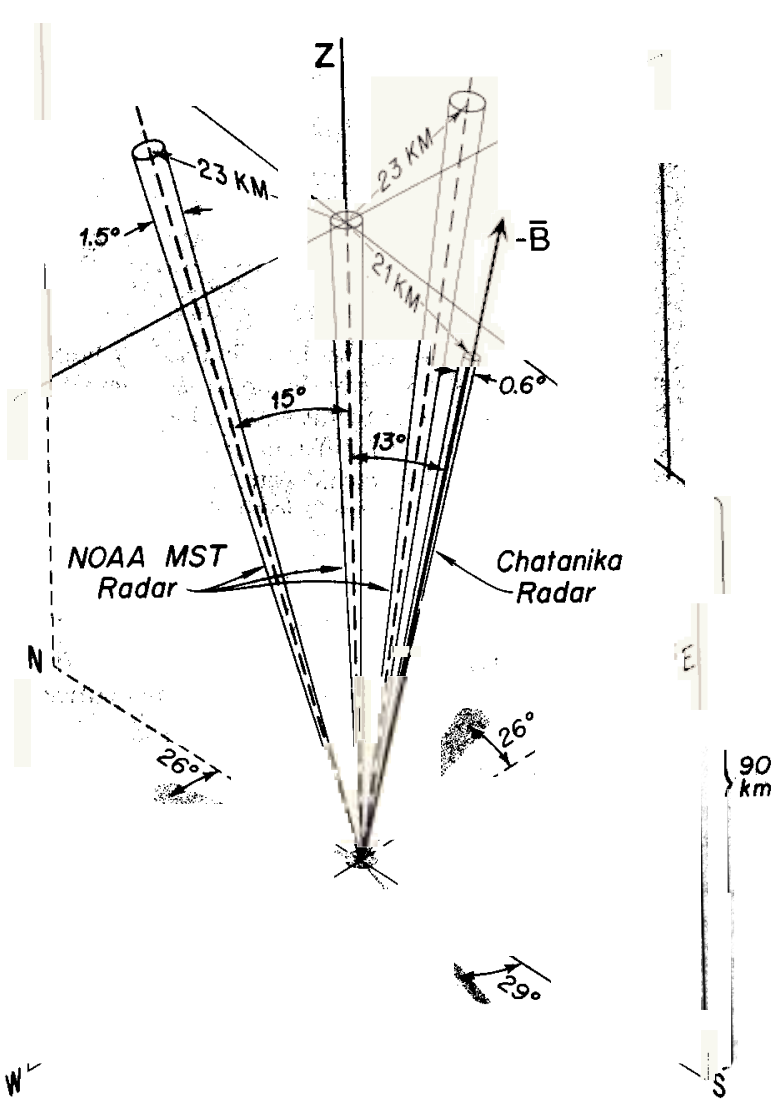

Fig. 1. Experiment configuration, showing the Chatanika radar beam directed along the local magnetic field and the three MST radar beams. Of the latter, one points vertically, while receiver 1 points in a northerly direction and receiver 2 points in an easterly direction. The MST radar is located approximately $2 \mathrm{~km}$ north of the Chatanika radar site. 

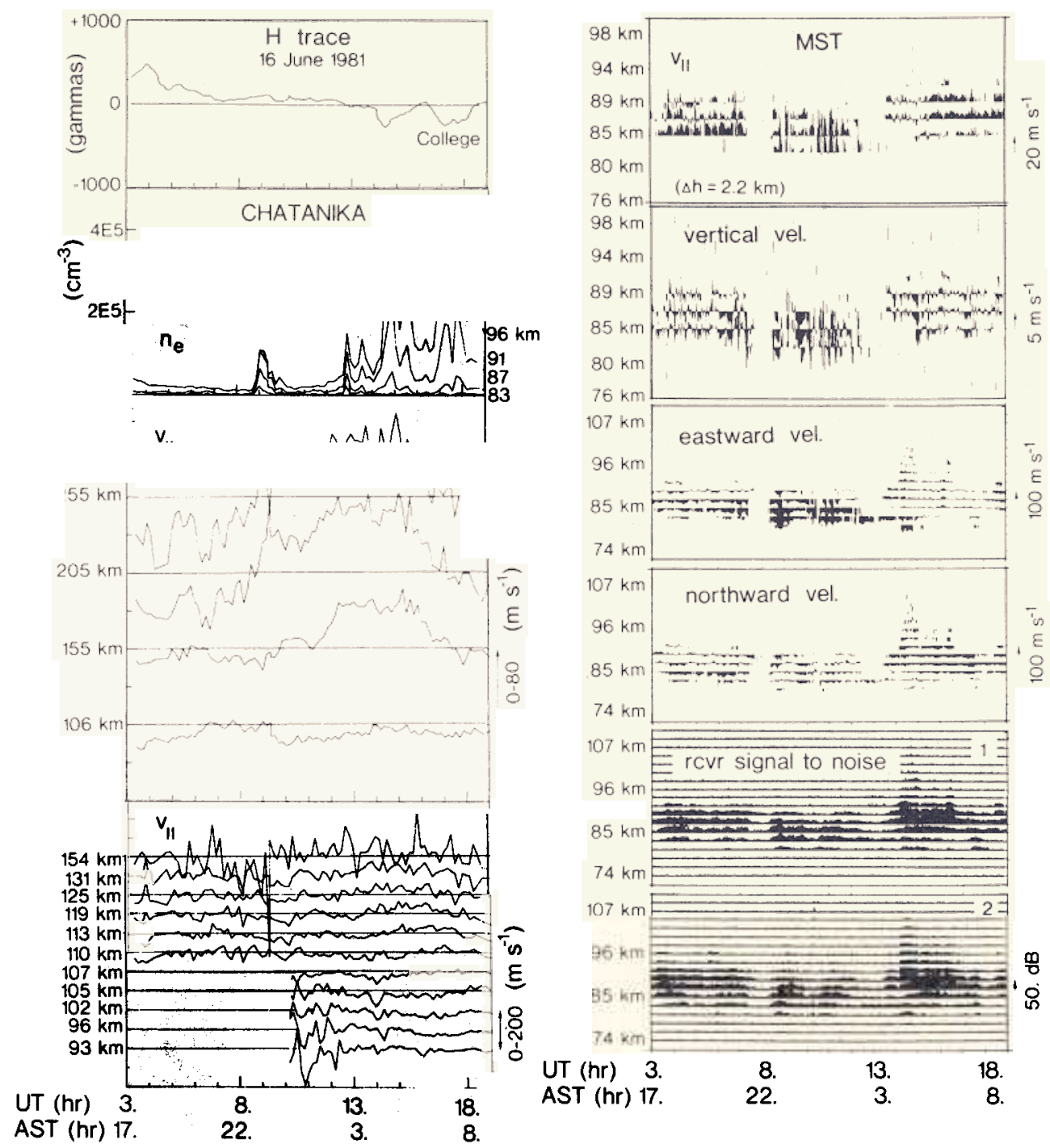

Fig. $2 a$

Fig. 2. Composite of the data obtained by both the incoherent scatter and VHF radars on (a) June 16, 1981 and (b) October 22, 1981. Starting at the upper left, these displays show the College magnetometer $H$ trace, the electron density at four alttitudes measured by the Chatanika radar, and the field-aligned component of the ion velocity $V_{\|}\left(=-\bar{V}_{i} \cdot \bar{B}\right.$ here $)$ at various altitudes at two different range resolutions (with different velocity scales). The MST radar data, shown (as histograms) on the left, include the velocity observed in the field-aligned, vertical, and geographic north and east directions, and the signal to noise ratios in the two oblique receivers.

Data obtained simultaneously with the Chatanika incoherent scatter radar and the Poker Flat MST radar provide the opportunity to answer some of these questions concerning the MST radar observations. In particular, plasma densities, density gradients, and electric fields can be obtained from incoherent scatter radar data, permitting tests of the dependence of VHF backscatter characteristics and 3-m irregularity motion on these parameters. This paper describes information obtained from two continuous 15 -hour periods of Chatanika radar and Poker Flat MST radar observations on June 16, 1981, and October 22, 1981. The analyses and results described here illustrate the possibilities for further comparisons.

\section{OBSERVATIONS}

The Chatanika incoherent scatter radar and the NOAA MST (VHF) radar have been described by Leadabrand et al. [1972] and Balsley et al. [1980], respectively. On summer nights at the latitude of Poker Flat $(\sim 65 \mathrm{~N})$, the ionosphere is locally produced by a combination of photoionization and auroral particle precipitation. The wintertime ionosphere is produced almost exclusively by the auroral precipitation source with some contribution from photoelectrons from the conjugate hemisphere.

During the local "nighttime" hours 0300-1800 UT (17000800 LT) of June 16, 1981, and October 22, 1981, experiments were carried out by using both radars in the configuration illustrated in Figure 1. The Chatanika radar was pointed toward the magnetic zenith, while the three MST radar beams (two oblique and one vertical) were fixed in their usual orientation as shown. The choice of the Chatanika radar fixed position was for the purpose of obtaining high time resolution thermospheric wind measurements with minimum contamination of the ion drifts by electric field effects. Altitude profiles of the plasma density with spatial resolution of $\sim 5 \mathrm{~km}$ were 


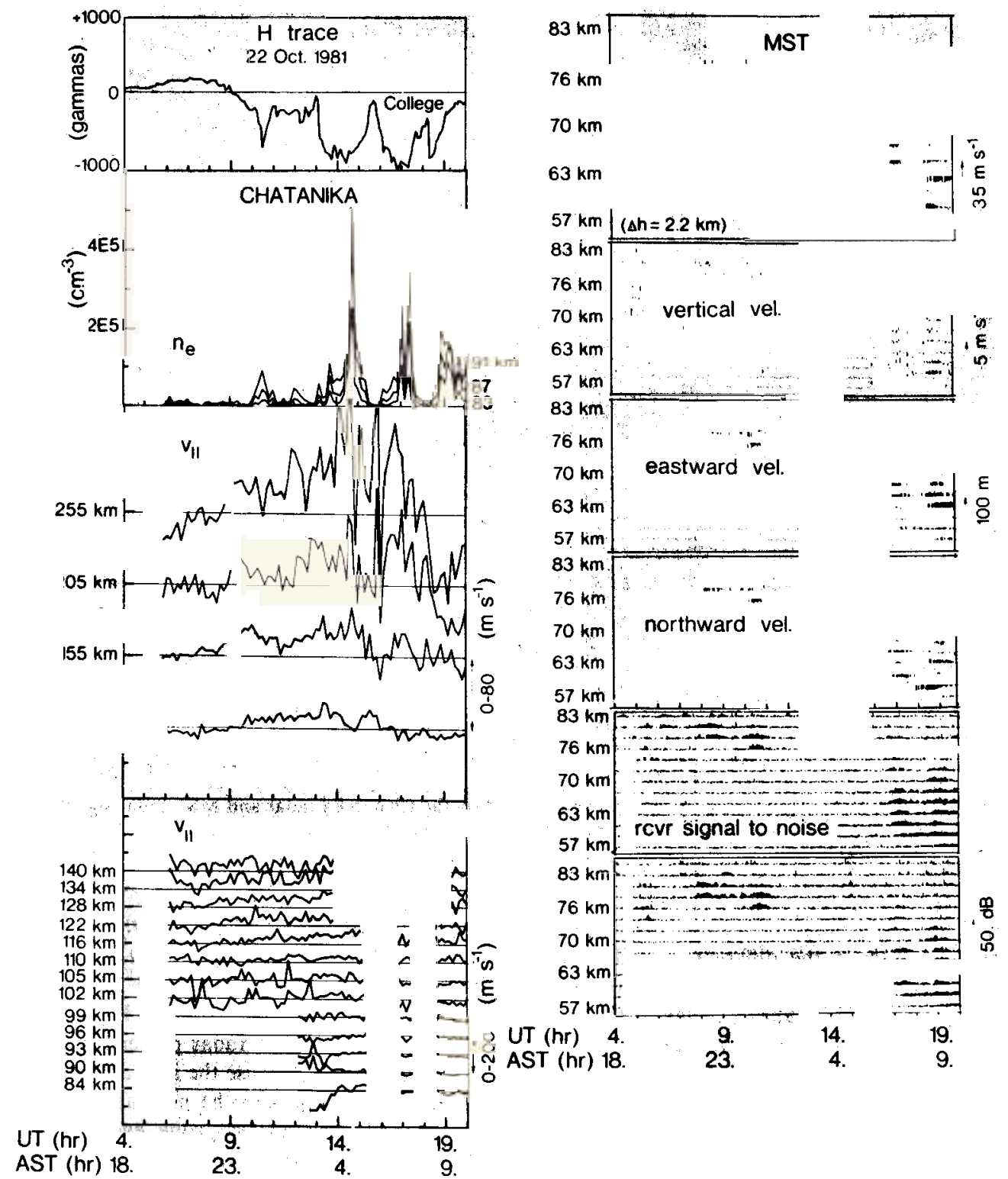

Fig. $2 b$

provided by these observations. The MST radar simultaneously obtained measurements of the mesospheric velocity with $2.2-\mathrm{km}$ height resolution during these periods of time, which were chosen because they represent typical summertime and wintertime conditions in the mesosphere.

A composite picture of the data for the two periods is given in Figure 2. The upper left-hand panel contains the $H$ component of the College magnetometer record during the radar experiment. The panel below the magnetogram shows $10-\mathrm{min}$ averages of the electron density measured by the Chatanika radar at four altitudes. Below the electron density, 10-min averaged magnetic field-aligned ion velocities $V_{\|}$obtained from the incoherent scatter signal are plotted for four $50-\mathrm{km}$ range intervals centered on the altitudes shown, and at higher range resolution for periods where the electron density was sufficient to produce a fairly accurate estimate with less spatial averaging. On the right side of Figure 2, the complementary MST velocity data and signal to noise ratios are displayed with approximately 2-min temporal resolution. In the top panel the component of the MST Doppler velocity parallel to the local magnetic field $\left(V_{\|}\right)$is shown. The geographic (vertical, eastward, and northward) component velocities and signal to noise ratios for the two oblique receivers complete the figure.

\section{Discussion}

It has been suggested [cf. Gage and Balsley, 1980] that mesospheric MST radar echoes occur when the electron density and the associated vertical gradient are sufficiently large, provided that neutral density irregularities in the $D$ region have a 3-m scale component. Ecklund and Balsley [1981] have described the regular seasonal variations in the mesospheric VHF echoes seen at Poker Flat. During the summer season (March-September) the VHF echoes are quite continuous in the altitude range $\sim 85-90 \mathrm{~km}$, while during the winter season (October -April) the echoes are sparse and tend to occur at lower altitudes $\sim 55-75 \mathrm{~km}$. The signal to noise data in 


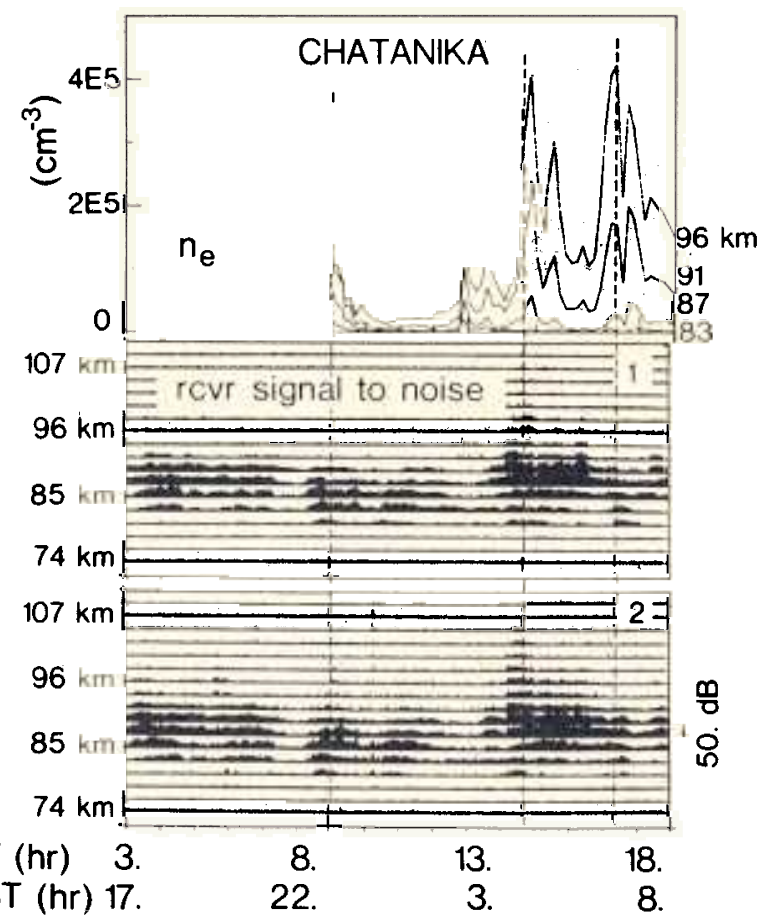

Fig. $3 a$

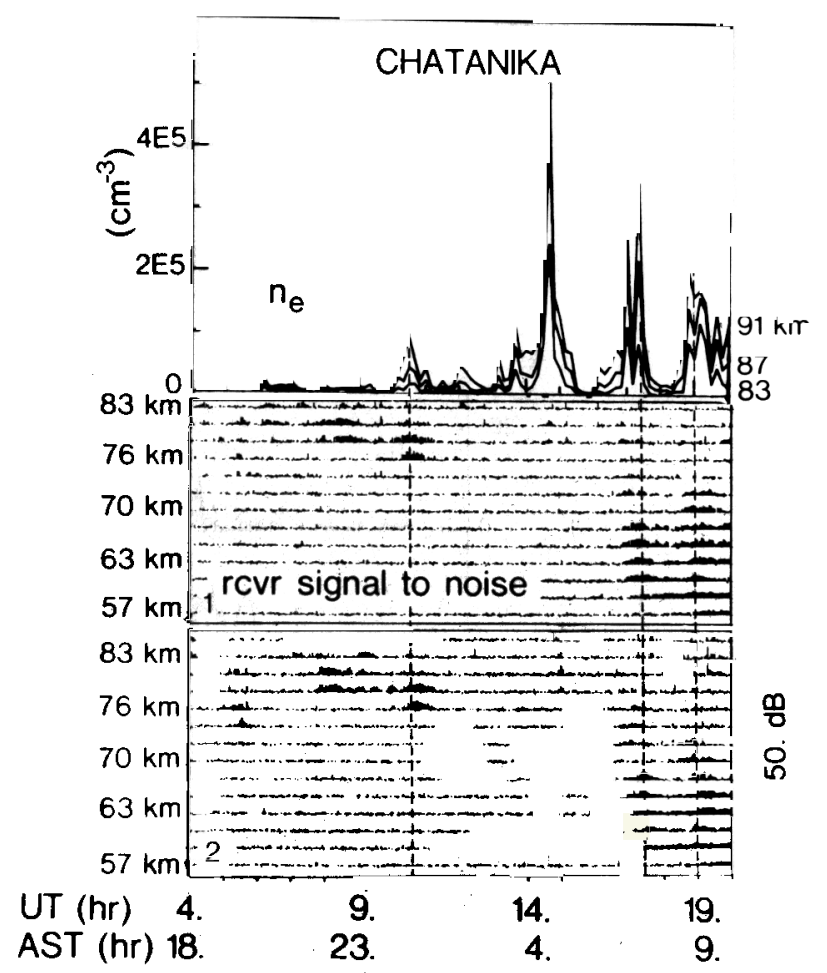

Fig. $3 b$

Fig. 3. (a) electron density below $100-\mathrm{km}$ altitude measured by the Chatanika radar and MST radar signal to noise ratio for the June 16 experiment. (b) Same as (a) but for October 22.

Figure 2 illustrate these typical seasonal characteristics, which have been attributed both to the differences in the neutral dynamics in winter and summer (turbulent breakdown of atmospheric tides [cf. Fritts et al., 1983] is believed to produce 3-m neutral density irregularities near the mesopause during the summer) and to the continuous photoionization source that is present in the summer at high latitudes. Examination of Figure 2 also reveals that during the negative bays visible on the College magnetometer records, the Chatanika radar data show auroral precipitation related increases in the electron densities and density gradients at the altitudes where the MST echoes originated. Details showing the comparison of the MST radar signal to noise ratio with the electron density data are given in Figure 3. Vertical lines have been superposed to mark features in the signal to noise record that correspond to the precipitation enhancements in ionization. The increase in signal to noise is seen at different altitudes for different events. Notably, the two events that occurred during local morning on October 22 had associated signal to noise enhancements, but the winter night event (at about $0400 \mathrm{AST}$ ) produced no apparent effect on the VHF echoes. Precipitation-related effects are more difficult to identify in the June data because of the higher quiet-time signal; however, they appear to be present in the summer also. This behavior is consistent with the expectation that the VHF backscatter depends in part on the local electron density in the $D$ region, except that the winter night event suggests that an additional factor must be necessary for the occurrence of echoes. The additional factor may be the state of the neutral atmosphere as previously suggested. Of course, it could be argued that the precipitation on this occasion was spatially nonuniform to the extent that the atmosphere within the Chatanika radar beam was affected but that within the MST radar beams was not or that the small amount of photoionization present on winter mornings is necessary for winter echoes.

Velocities determined from the Doppler shifted frequencies of backscattered MST radar power are usually interoreted as neutral velocities because the ions at the altitude of the echoes are strongly coupled to the neutral atmosphere by collisions. However, in the auroral zone even the low-altitude ionospheric plasma can be influenced by the occasionally strong local electric fields that are related to magnetospheric convection. The electric field strength at a particular time can be estimated from the combination of magnetometer data and electron density data by using the formulae [cf. Banks and Doupnik, 1975],

$$
\begin{gathered}
\Delta D=-\mu_{0}\left(\Sigma_{p} E_{N}^{\prime}-\Sigma_{H} E_{E}^{\prime}\right) \\
\Delta H=\mu_{0}\left(\Sigma_{H} E_{N}^{\prime}+\Sigma_{p} E_{E}\right)
\end{gathered}
$$

where $\Delta D$ and $\Delta H$ are the usual geomagnetic perturbations, $\mu_{0}$ is the permeability, $\Sigma_{p}$ and $\Sigma_{H}$ are the height-integrated Pedersen and Hall conductivities, respectively (which require the electron density altitude profile and a neutral atmosphere model for their evaluation) and the electric fields, which include the dynamo field $\left(\bar{E}^{\prime}=\bar{E}+\bar{u} \times B, \bar{u}=\right.$ neutral wind) are separated into magnetic eastward and northward components (subscripts $E$ and $N$ ). Although these expressions strictly apply only to an infinite plane current sheet overhead, whereas the currents may in fact be concentrated within auroral arcs, the accuracy of this method of inferring the electric field has been demonstrated for several cases by Banks and Doupnik [1975]. Horizontal electric fields for the period under consideration here, calculated by this method using 10-min averaged elec- 


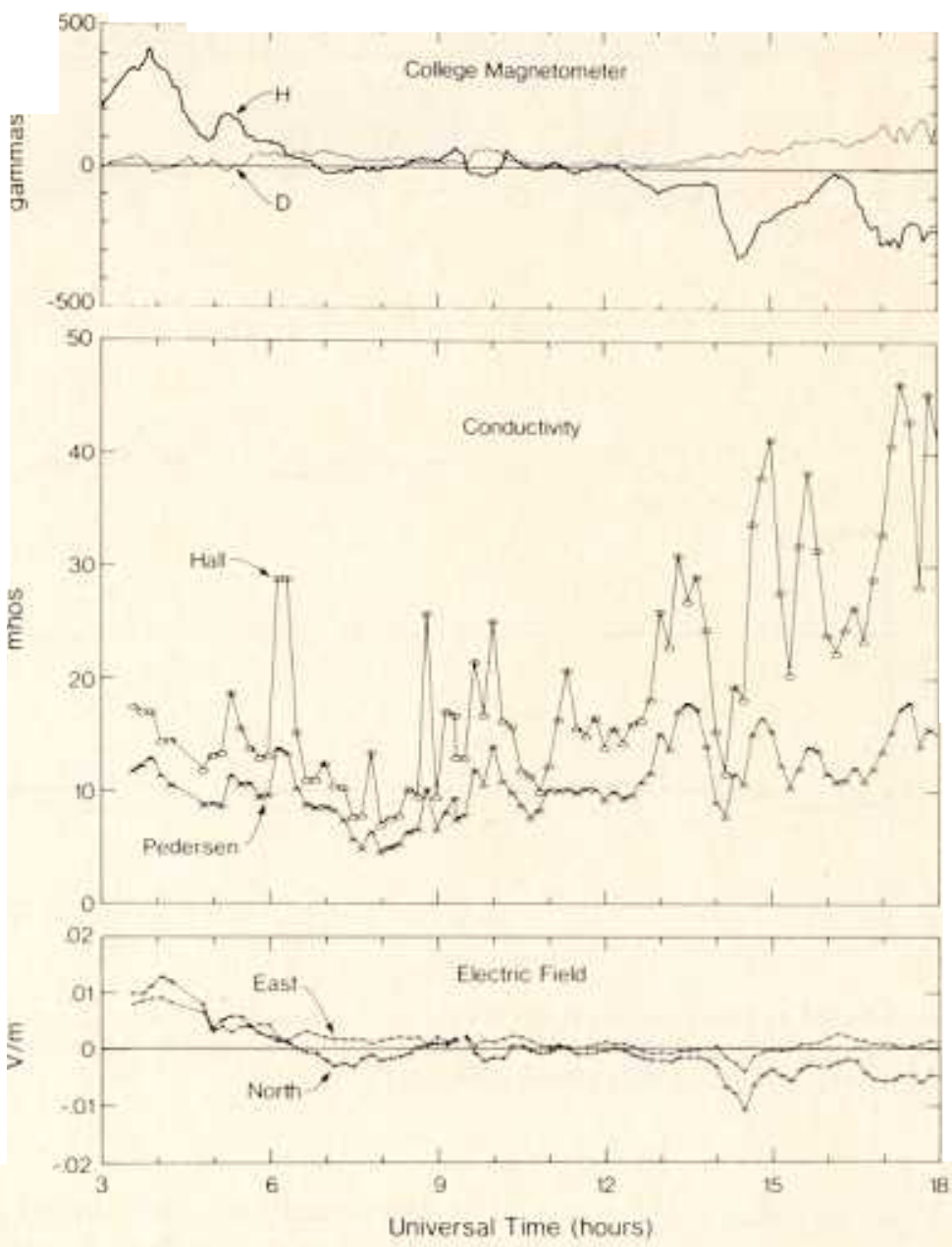

Fig. 4. From top to bottom: $\Delta H$ and $\Delta D$ at College; height-integrated conductivity calculated from the 10-min averaged electron density profiles measured by the Chatanika radar and the Cira (1972) neutral atmosphere model, and the resulting horizontal electric fields (magnetic coordinates) obtained by using the formulae in the text.

tron density profiles measured by the Chatanika radar and the Cira (1972) neutral atmosphere model for the conductivity, are shown in Figure 4. The interpretation of the MST velocities as neutral velocities can now be addressed using the inferred electric fields. If it is assumed that the observed velocity of the VHF scattering irregularities is equal to the ion velocity, which is practically true for non-field-aligned plasma density irregularities [Reid, 1983], the neutral velocity can be approximated by the expression

$$
\bar{u} \simeq \bar{v}-\frac{1}{m_{i} v_{i n}}(\bar{E}+\bar{v} \times \bar{B})
$$

where $\bar{v}$ is the ion velocity (=MST velocity), $e$ is the electron charge, $m_{i}$ is the ion mass, $v_{i n}$ is the ion-neutral collision frequency, $\bar{B}$ is the magnetic field, and $\bar{E}$ is the inferred electric field $\bar{E}^{\prime}$ discussed above (e.g., the dynamo contribution is assumed small). The difference between $\bar{u}$ and the observed velocity $\bar{v}$ is then a measure of the influence of the Lorentz force on the ions at the VHF scattering altitude. Comparisons between calculated $\bar{u}$ and observed $\bar{v}$ are given in Figure 5 by the differences $(\bar{u}-\vec{v})$ for the horizontal velocity components at 86-km altitude. The computed electric field shown in Figure 4 was used in the calculation of $\bar{u}$. The results in Figure 5 suggest that the electric fields that occur in the auroral zone can partially decouple the ion and neutral components of the atmosphere at $86-\mathrm{km}$ altitude. However, because the difference between the ion and neutral velocities is small $\left(\$ 1 \mathrm{~m} \mathrm{~s}^{-1}\right)$ in comparison with the typical horizontal velocities $(\sim 10-50 \mathrm{~m}$ $\mathbf{s}^{-1}$ ) observed by the MST radar, the interpretation of the observed horizontal velocities at $\sim 85-\mathrm{km}$ altitude as mesospheric neutral winds is justified. Still, this interpretation must be made with caution in cases where the observed velocities are small and the electric field magnitudes (as indicated by magnetometer activity, for example) approach their maximum auroral zone values of $\geq 100 \mathrm{mVm}^{-1}$. In particular, Reid [1983] pointed out that the vertical velocity, which is always small, cannot be interpreted as a neutral velocity during periods of auroral activity.

A particularly interesting aspect of these data from the UHF and VHF radars from the viewpoint of upper and lower atmosphere coupling is the practically continuous measurement of the neutral velocity component parallel to the magnetic field from $\sim 50$ - to $80-\mathrm{km}$ altitude to $\sim 300 \mathrm{~km}$. In particular, the summer high resolution UHF parallel velocity data (lower left-hand side of Figure 2) when joined with the VHF data (upper right) suggest a vertical wavelength in the long-period variations of $\sim 20 \mathrm{~km}$ that is consistent with what is expected for certain atmospheric tides at these altitudes [Holton, 1975; Forbes, 1982]. Figure 6 shows this detail of Figure 2 on a larger scale, together with the vertical velocity. 


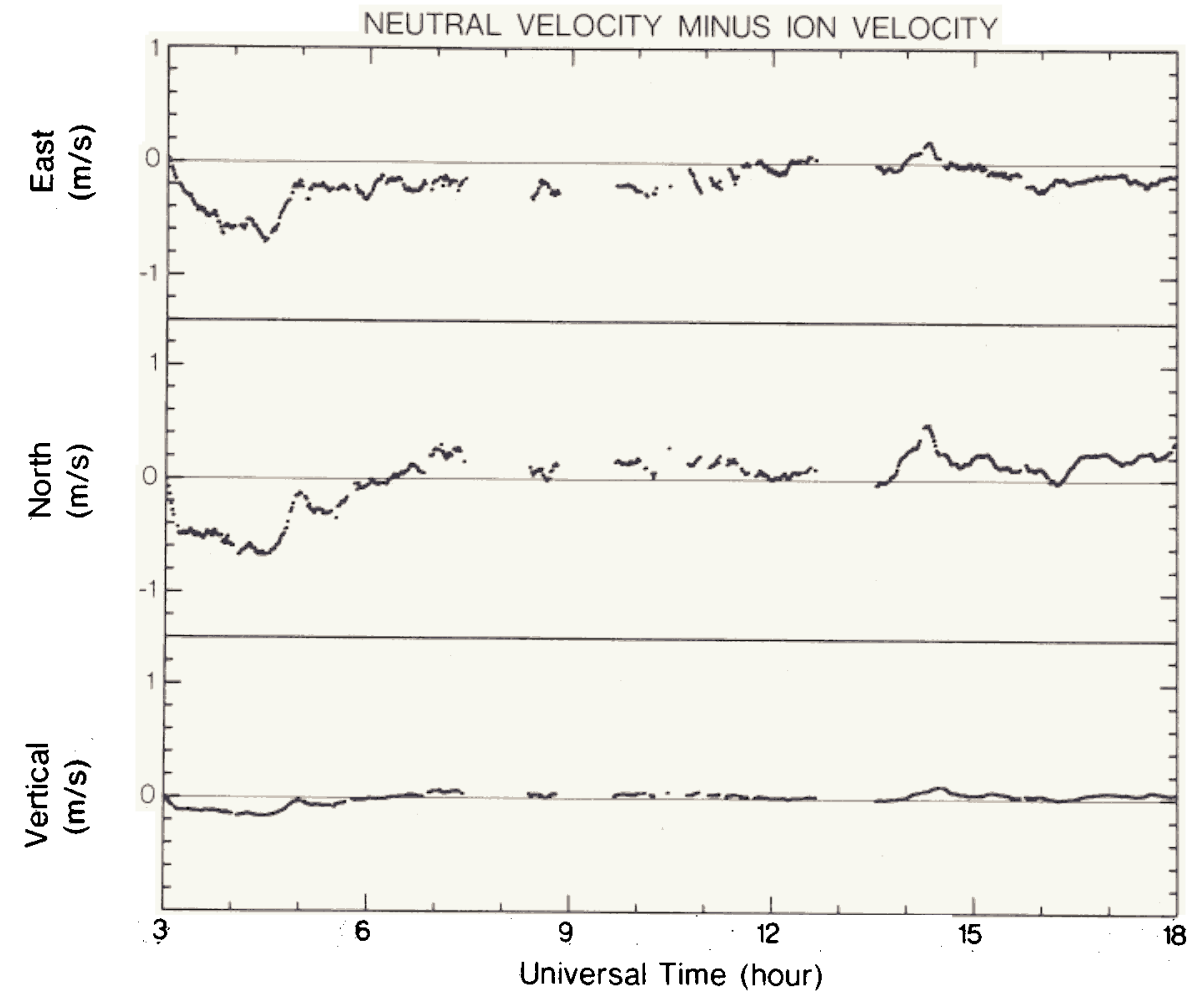

Fig. 5. Differences between (magnetic) eastward, northward, and vertical MST velocity components at $86 \mathrm{~km}$ and the neutral velocity calculated under the assumption that the observed velocity is equal to the ion velocity. The values of the neutral velocity were obtained by using the electric fields shown in Figure 3.

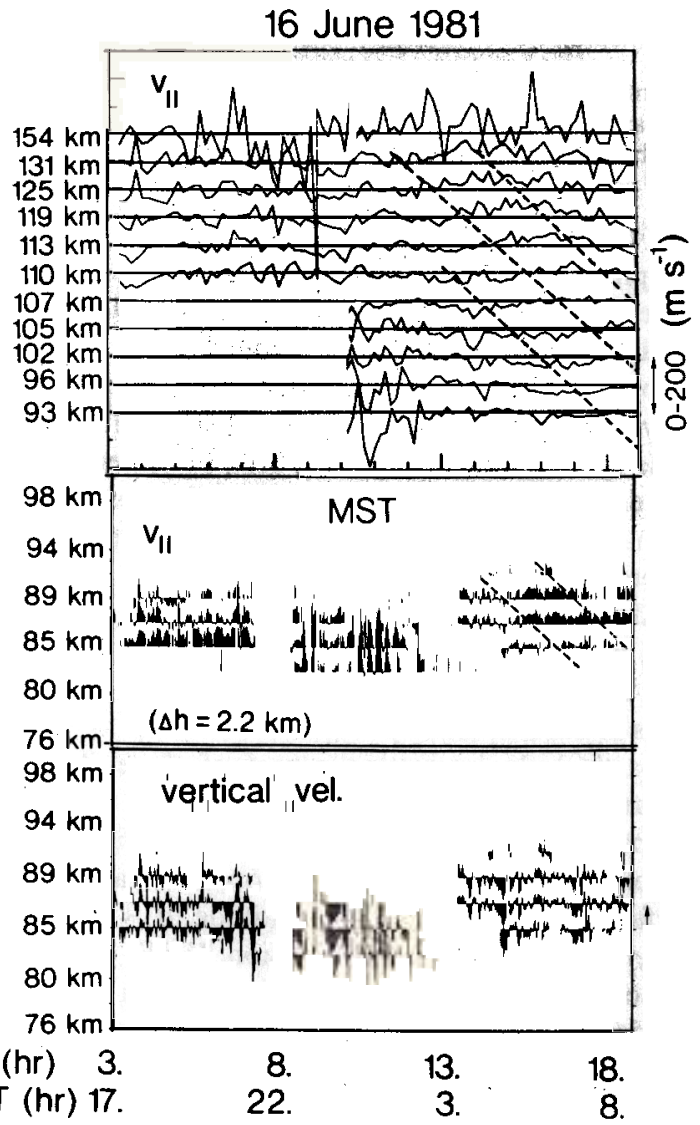

Fig. 6. Detail from Figure 2, with dashed lines indicating what may be phase fronts of a propagating gravity wave or tidal structure.
The dashed lines guide the eye through phase fronts of one vertical wave cycle. Both the summer and winter data exhibit a similar diurnal behavior of $V_{||}$at altitudes above $\sim 130 \mathrm{~km}$. Assuming that the vertical wind is much smaller than the parallel component of the horizontal wind, the measurements indicate that the thermospheric wind is strongly southward near local midnight and in the early morning hours and northward in the evening and near dawn. The summer highresolution data mentioned above suggest that this nighttime southward surge in the upper thermospheric wind merges with the diurnal tide in the lower thermosphere. Since Wickwar [1981] demonstrated that the magnitude of the southward wind above $\sim 150 \mathrm{~km}$ is related to the geomagnetic and auroral activity index $K p$, the diurnal tide that is seen at the lower altitudes may also be affected by geomagnetic activity if the tides in the upper and lower thermosphere are coupled.

\section{CONCluding Remarks}

The advantages of combined analyses of incoherent scatter radar and MST radar data for the purpose of understanding the structure and dynamics of the plasma in the low-altitude auroral zone ionosphere and the nature of VHF backscatter from the mesosphere are apparent. The observations described above demonstrate that the background electron density is important in the generation of VHF echoes but that another ingredient such as neutral turbulence is also a factor. Altitude profiles of the magnetic field-aligned ion velocity from the $F$ region to the $D$ region obtained with both radars show how the diurnal tide in the neutral wind behaves from the thermosphere through the mesosphere.

Although the Chatanika radar has been moved from its 
Alaska site, many other types of incoherent scatter radar data were obtained at times overlapping the period of operation of the Poker Flat MST radar. These data, which include some direct observations of the vector electric field derived from three-position measurements of the $F$ region plasma drift, can be utilized in future studies. Moreover, considering that mesospheric velocity data obtained by the Poker Flat MST radar are affected to some degree by magnetospheric convection electric fields, the Chatanika radar incoherent scatter data can be used to eliminate periods of strong fields from MST radar data that are included in neutral wind studies.

Acknowledgments. The College magnetometer data were kindly provided by S. I. Akasofu and his staff at the Geophysical Institute, University of Alaska. One of the authors (JGL) also benefited from discussions with R. Hunsucker, G. C. Reid, W. L. Ecklund, and V. B. Wickwar. Support of the Chatanika radar experiment by members of the SRI International, including $M$. Lemmons, M. McCready, F. Steenstrup, O. de la Beaujardiere, and J. Kelly is gratefully acknowledged. This work was supported by NOAA grant NA-81-RA-00010. The Poker Flat Radar is supported by the Atmospheric Sciences Section of the National Science Foundation.

The Editor thanks the referee for his assistance in evaluating this paper.

\section{REFERENCES}

Avery, S. K., B. B. Balsley, and A. C. Riddle, The Poker Flat, Alaska, MST radar as a metor radar, Radio Sci., 18 in press, 1983.

Balsley, B. B., W. L. Ecklund, D. A. Carter, and P. E. Johnston, The MST radar at Poker Flat, Alaska, Radio Sci., 15, 213, 1980.

Banks, P. M., and J. R. Doupnik, A review of auroral zone electrodynamics deduced from incoherent scatter radar observations, $J$. Atmos. Terr. Phys., 37, 951, 1975.

Ecklund, W. L., and B. B. Balsley, Long-term observations of the
Arctic mesosphere with the MST radar at Poker Flat, Alaska, $J$. Geophys. Res., 86, 7775, 1981.

Fritts, D. C., B. B. Balsley, and W. L. Ecklund, Evidence of gravity wave and tidal breakdown at the summer mesopause submitted to Radio Sci., 1983.

Forbes, J. M., Atmospheric tides, 1, Model description and results for the solar diurnal component, J. Geophys. Res., 87, 5222, 1982.

Gage, K. S., and B. B. Balsley, On the scattering and reflection mechanisms contributing to clear air radar echoes from the troposphere, stratosphere and mesosphere, Radio Sci., 15, 243, 1980.

Holton, J. R., The Dynamic Meteorology of the Stratosphere and Mesosphere, American Meteorological Society, Boston, 1975.

Leadabrand, R. L., M. J. Baron, J. Petriceks, and H. F. Bates, Chatanika, Alaska, auroral zone incoherent scatter facility, Radio Sci., 7, 747, 1972.

Reid, G. C., The influence of electric fields on radar measurements of winds in the upper mesosphere, Radio Sci., 18 , in press, 1983.

Reid, G. C., B. B. Balsley, W. L. Ecklund, and J. G. Luhmann, On the mechanisms responsible for MST radar echoes from the highlatitude mesosphere (abstract), Eos Trans. $A G U, 62,875,1981$.

Röttger, J., Structure and dynamics of the stratosphere and mesosphere revealed by VHF radar investigations, Pure Appl. Geophys., $118,494,1980$.

Wickwar, V. B., Auroral region dynamics determined with the Chatanika radar, SRI Proj. Rep. 6897, SRI International, Menlo Park, Calif., 1981.

B. B. Balsley and A. C. Riddle, Aeronomy Laboratory, NOAA Environmental Research Laboratories, Boulder, CO 80303.

M. J. Baron, EISCAT Scientific Association, Kiruna, Sweden.

R. M. Johnson and J. G. Luhmann, Institute of Geophysics and Planetary Physics, University of California, Los Angeles, CA 94025.

(Received May 9, 1983;

revised August 16, 1983; accepted August 19, 1983.) 